\title{
El cuidado del cuerpo en el arte, la ciencia y la filosofía de la enfermería
}

\section{Body and Care in Art, Science, and Philosophy of Nursing Corpo e cuidado na arte, ciência e filosofia de enfermagem}

Carlos Roberto Carlos Fernandes ${ }^{1}$, Isaura Setenta Isaura Porto ${ }^{2}$, André Marcelo Machado Soares ${ }^{3}$

${ }^{1}$ Universidade Federal do Espírito Santo (UFES), doutor em Enfermagem, professor de Magistério Superior.

${ }^{2}$ Universidade Federal do Rio de Janeiro (UFRJ), doutora em Enfermagem, professora de Magistério Superior.

${ }^{3}$ Fundação Oswaldo Cruz (FIOCRUZ), doutor em Teologia, professor de Magistério Superior

Cómo citar este artículo en edición digital: Fernandes, C.R., Porto, I.S., Soares, A.M. M.(2017). El cuidado del cuerpo en el arte, la ciencia y la filosofía de la enfermería. Cultura de los Cuidados (Edición digital), 21(47).

Recuperado de http://dx.doi.org/10.14198/cuid.2017.47.08

Correspondencia: Universidad Federal do Rio de Janeiro. Escola de Enfermagem Anna Nery da Universidade Federal do Rio de Janeiro Universidade Federal do Rio de Janeiro.

Correo electrónico: isaura70porto@gmail.com

Recibido: 27/04/2016; Aceptado: 11/010/2016

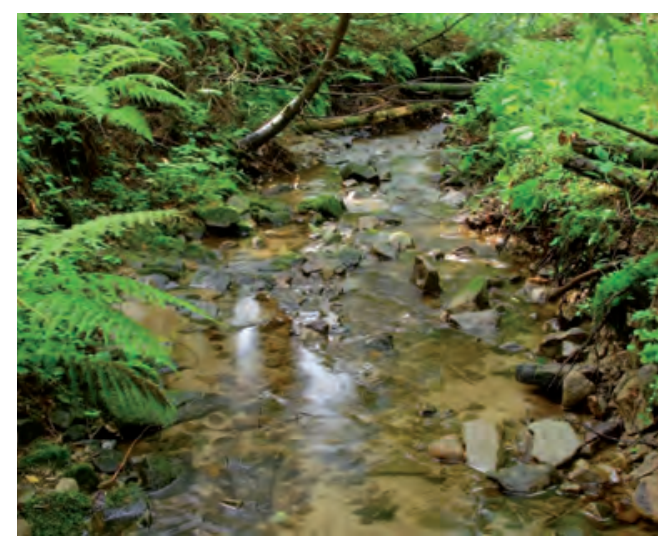

\section{ABSTRACT}

The research objectives are to clarify the theoretical origin of so-called Nursing metaparadigmas, explicit kinds of seconds Wilhelm Dilthey worldviews on the paradigm concept in Thomas Kuhn, propose two nouns concepts identified in national Nursing writings. The research is theoretical, the method is inductive, the technique is descriptive-analytic and the approach is historical. Results: the apparent consensus on the Nursing metaparadigmas is more didactic than coming from refined epistemological research; there is no concep- tual similarity of metaparadigm of meanings in Margaret Mastermann and designing metaparadigmas in nursing; the notion of paradigm in Thomas Kuhn has similarities to the earlier theory of world views in Wilhelm Dilthey. Purposeful conclusion: body and care are nouns concepts; therapeutic relationship is connective concept; Nursing care is adjective concept. The three types of concepts has been the fundamental connection experience (Erlebnis). If having for object of study the mediator body of nursing care, in Aristotelian terms it can be said that the body is material cause, the mediator body is formal cause, the therapeutic relationship in the care process is efficient cause, care Nursing is final cause.

Keywords: Metaparadigm, care, body, nursing care, nursing.

\section{RESUMO}

Os objetivos desta investigação são esclarecer a procedência teórica dos chamados metaparadigmas de Enfermagem, explicitar os tipos de concepções de mundo segundo Wilhelm Dilthey diante da concepção de paradigma em 
Thomas Kuhn, propor dois conceitos substantivos identificados em escritos nacionais de Enfermagem. A investigação é teórica, o método é indutivo, a técnica é descritivo-analítica e a abordagem é histórica. Os resultados encontrados são: o aparente consenso sobre os metaparadigmas de Enfermagem não procedem de apurada investigação epistemológica; não há similaridade conceitual das significações de metaparadigma em Margaret Mastermann e a concepção de metaparadigmas na Enfermagem; a noção de paradigma em Thomas Kuhn tem semelhanças com a anterior teoria de concepções de mundo em Wilhelm Dilthey. As conclusões propositivas são: corpo e cuidado são conceitos substantivos; relacionamento terapêutico é conceito conjuntivo; cuidado de Enfermagem é conceito adjetivo. Aos três tipos de conceitos tem-se a conexão fundamental da vivência (Erlebnis). Tendo-se por objeto de estudo o corpo mediador do cuidado de Enfermagem, em termos aristotélicos pode-se dizer que o corpo é causa material, o corpo mediador é causa formal, o relacionamento terapêutico no processo de cuidado é causa eficiente, $o$ cuidado de Enfermagem é causa final.

Palavras-chave: Metaparadigma, cuidado, corpo, cuidado de enfermagem, enfermagem.

\section{RESUMEN}

Los objetivos de la investigación consisten en clarificar el origen teórico de los llamados metaparadigmas de Enfermería, aclarar los tipos de concepciones del mundo segundo de Wilhelm Dilthey en relación al concepto de paradigma en Thomas Kuhn, proponer dos conceptos sustantivos identificados en los escritos nacionales de enfermería. La investigación es teórica, el método es inductivo, la técnica es descriptivo-analítica y el enfoque es histórico. Los resultados son: lo consensos sobre los metaparadigmas de Enfermería son solamente aparentes en el contexto de una investigación epistemológica refinada; no existe similitud conceptual de significados de metaparadigma en Margaret Mastermann y su uso en la enfermería; el paradigma en Thomas Kuhn tiene similitudes con la teoría anterior de concepciones del mundo en Wilhelm Dilthey. Las propuestas concluyentes son: el cuidado y el cuerpo son conceptos sustantivos; la relación terapéutica es un concepto conectivo; el cuidado de enfermería es concepto adjetivo. Los tres tipos de conceptos tienen por conexión fundamental el concepto de vivencia (Erlebnis). Si tener por objeto de estudio el cuerpo mediador de los cuidados de enfermería, en términos aristotélicos se puede decir que: el cuerpo es causa material, el cuerpo mediador es causa formal, la relación terapéutica en el proceso de cuidado es causa eficiente, el cuidado de enfermería es causa final.

Palabras clave: Metaparadigma, cuidado, cuerpo, cuidado de enfermería, enfermería

\section{INTRODUÇÃO}

Pela influência da concepção de paradigma do físico estadunidense Thomas Samuel Kuhn, com a publicação de sua obra The structure of scientific revolutions, no ano de 1962, pesquisadoras de Enfermagem, desde o início dos anos de 1970, têm se dedicado a criar ou identificar os seus paradigmas, metaparadigmas, conceitos, meta-conceitos e até buscar consensos a partir da produção de modelos conceituais e teorias de Enfermagem.

Num quase consenso e sob a influência de enfermeiras norteamericanas apresentam-se os denominados metaparadigmas pessoa, saúde, ambiente e Enfermagem. Estes quatro conceitos, ainda não sistematicamente definidos, 
aparecem como uma espécie de "fio de navalha" para identificar o uso e a concepção dos mesmos nos modelos conceituais e nas teorias de Enfermagem.

Um primeiro complicador é a replicação acrítica daqueles quatro conceitos, mediante um aparente ou prematuro consenso. Um segundo complicador é a aplicação daqueles modelos conceituais e teorias de forma a-histórica, negligenciando os caminhos diferentes e concepções de mundo até divergentes, por exemplo, entre a Enfermagem britânica, francesa, estadunidense, hispânica e brasileira. Os dois complicadores apontados trazem à tona as possíveis distorções e confusões conceituais quando se buscam ou se forjam apressadas generalizações, desatentas ao que pode ser chamado de princípio de historicidade (historizität) pelo qual emergem, se configuram, se desenvolvem, se hegemonizam e fenecem determinadas e históricas concepções de arte, de filosofia, de religião, de ciência.

Perante tais questões e após a análise apurada de 120 textos nacionais de Enfermagem, entre livros, artigos, dissertações e teses previamente selecionados para a pesquisa de doutoramento em curso, tem-se por objetivos: esclarecer a procedência teórica dos chamados metaparadigmas de Enfermagem; explicitar os tipos de concepções de mundo segundo Wilhelm Dilthey diante da concepção de paradigma em Thomas Kuhn; propor dois conceitos substantivos identificados em escritos nacionais de Enfermagem.

\section{MÉTODO}

A investigação é teórica, o método é indutivo, a técnica é descritivo-analítica e a abordagem é histórica. Teórica é a pesquisa "dedicada a reconstruir teoria, conceitos, idéias, ideologias, polêmicas, tendo em vista, em termos imediatos, aprimorar fundamentos teóricos" (Demo, 2000, p. 20). Ainda, o "conhecimento teórico adequado acarreta rigor conceitual, análise acurada, desempenho lógico, argumentação diversificada, capacidade explicativa" (Demo, 1994, p. 36).

A técnica descritivo-analítica caracteriza-se pela

descrição e análise de uma conexão que se nos dá sempre de modo originário, como a vida mesma [e, por isso,] tem por objeto as regularidade na conexão da vida psíquica desenvolvida. [...] Observa, analisa, explicita e compara [e] toda conexão utilizada pode ser verificada univocamente mediante a percepção interna e toda conexão semelhante pode mostrar-se como membro da conexão mais ampla, total, não inferida, mas originalmente dada (Dilthey, 1951, p. 204).

A característica da observação, da análise, da explicitação e da comparação na técnica descritivo-analítica para apreender uma conexão originária e não inferida expressa o próprio método indutivo utilizado.

O processo compreensivo apreendido como indução é comum às Ciências da Natureza (Naturwissenschaften) e às Ciências do Espírito (Geisteswissenschaften) e esta indução "pertence à classe na qual não se deriva uma lei universal de uma série incompleta de casos, mas na qual se deriva desses casos uma estrutura, um sistema ordenado reunidor dos casos como partes em relação a um todo" (Ditlhey, 1914; 2010, p. 204; 2012).

Ratificando e particularizando, nas Ciências do Espírito (Humanas e Sociais), a compreensão é "uma indução que deduz das particularidades parcialmente determinadas para 
nós uma conexão definidora do todo" (Dilthey, 1914; 2010, p. 214; 2012). Essa "conexão definidora do todo" é a expressão da própria vida (mundo humano-sócio-histórico) porque esta, original e imanentemente, é conexão ( $Z u$ sammenhang), totalidade. Não se trata, pois, de criar unidades temáticas, de significado ou de sentido mediante captação de núcleos de conteúdos assemelhados, mas de captar uma estrutura (Struktur) viva e, portanto, histórica.

O percurso descritivo se dará a partir da seleção, em obras específicas das concepções de seus autores sobre paradigma, metaparadigma e teoria das concepções de mundo; nas obras previamente selecionadas de Enfermagem buscar-se-á a explicitação dos denominados metaparadigmas de Enfermagem.

O passo um é o da observação, onde observar significa "direção da atenção a algo colocado-diante-de-mim" (Dilthey, 1986, p. 100); consiste na própria busca dos conceitos de paradigma, metaparadigma e teoria das concepções de mundo. O passo dois é da explicitação e consiste no destaque e retomada daqueles conceitos. O passo três é o da comparação entre as concepções dos autores selecionados, relativas àqueles conceitos.

O percurso analítico e que entre aspas pode ser chamado de passo quatro é conexo ao comparativo e tem por fundamento as operações lógicas primárias ou formais: ao comparar, relaciona, distingue, estabelece graus de diferença ou semelhança, "deriva relações uniformes, partindo de casos isolados, analisa processos em particular, divide ou classifica” (Dilthey, 1951, p. 224). Tais operações lógicas primárias ou formais "captam relações e não conteúdos, objetos, processos" (Dilthey, 1944, p. 87).

Das operações próprias do pensamento tácito procedem as operações lógicas do pensamento discursivo, diferenciadas e aperfei- çoadas: os movimentos de igualar preparam a "formação dos juízos gerais, os conceitos gerais e o método comparado. [...] [os de separar preparam] abstrações e o método analítico" (Dilthey, 1944, p. 145-6). O movimento de relacionar prepara a operação de sintetizar, própria do pensamento interpretativo.

No percurso analítico se dá a proposição dos conceitos substantivos, resultantes da análise prévia dos textos de Enfermagem e pre-selecionados no doutoramento. Esses textos, de 1984 a 2014, compõem-se de 120 obras nacionais, entre artigos, dissertações, teses e livros sobre corpo. Como todos estes textos foram previamente analisados, são aqui considerados e não detalhados para se chegar à proposição dos conceitos substantivos.

A abordagem é histórica porque todas as operações e movimentos lógicos buscam a “conexão que se nos dá sempre de modo originário, como a vida mesma [e, por isso,] têm por objeto as regularidades na conexão da vida psíquica desenvolvida”. Nesta investigação, vida significa estritamente "mundo humano, histórico e social" e história "é realização da vida no curso do tempo e na simultaneidade" (Ditlhey, 1951, p. 204, 362, 364; 1986, p. 236).

\section{RESULTADOS E DISCUSSÃO}

\section{Conceitos centrais e metaparadigmas}

Em linguagem mais ou menos consensual, pelo menos do ponto de vista norteamericano, sugerem-se focos de interesse investigativo da Enfermagem expressos em termos de conceitos centrais. Uma destas primeiras sugestões é a revisão de Fawcett (1984) de dez concepções de pesquisadoras de Enfermagem, num período entre 1971 e 1983, congregando tais concepções sob o título de conceitos centrais:

a - "Pode-se [...] demarcar a enfermagem em termos de quatro subconjuntos : 1) As pes- 
soas prestadoras de cuidado, 2) pessoas com problemas de saúde que recebem cuidado, 3) o ambiente em que o cuidado é dado, e 4) um estado final, o bem-estar" (Walker, 1971, p. 429);

b - "Os principais conceitos identificados a partir da análise dos componentes, temas, tópicos e subtópicos de modelos conceituais de 50 programas de bacharelado de enfermagem foram Homem, Sociedade, Saúde e Enfermagem" (Yura e Torres, 1975, p. 22);

c - "A enfermagem estuda a integridade ou a saúde dos seres humanos, reconhecendo que os mesmos estão em contínua interação com seus ambientes" (Donaldson e Crowley, 1978, p. 119);

d - "O foco da enfermagem são as pessoas, seus ambientes, sua saúde e a própria enfermagem” (Bush, 1979, p. 20);

e - "Os elementos de Enfermagem são atos de enfermagem, o paciente e a saúde" (Stevens, 1979, p. 11);

f - "Os focos de enfermagem são o indivíduo em relação à saúde, o ambiente e do processo de mudança, seja de maturação, adaptação ou enfrentamento" (Barnard, 1980, p. 208);

g - "Enfermagem é definida como o diagnóstico e o atendimento das respostas humanas, atuais ou potenciais, aos problemas de saúde" (ANA, 1980, p. 9);

h - Quatro são as áreas conceituais ou meta-conceitos para o desenvolvimento de teorias de Enfermagem: o ambiente existente dentro da pessoa; o processo saúde-doença dentro do qual a pessoa está no momento da interação com a enfermeira; as ações de enfermagem (Flaskerud e Halloran, 1980);

i - "O domínio de enfermagem inclui sempre a enfermeira, o paciente, a situação em que se encontram, e a sua finalidade de ser em conjunto, ou a saúde do paciente. Em termos mais formais, $[\ldots]$ os principais componentes, (meta) paradigma da enfermagem são Enfermagem (como uma ação), o cliente (ser humano), meio ambiente (do cliente e do enfermeiro-cliente) e saúde" (Newman, 1983, p. 388);

j - "Há um consenso geral de que os conceitos centrais da disciplina de enfermagem são a natureza da enfermagem, o indivíduo que recebeu o cuidado de enfermagem, a sociedade-ambiente e saúde" (Chinn, 1983, p. 396).

Ao destacar tais investigações, Fawcett (1984) sugere que os conceitos saúde, ambiente, Enfermagem e indivíduo são metaparadigmas de Enfermagem, ainda que as declarações assinaladas não sejam absolutamente convergentes àqueles quatro conceitos. Posteriormente, Fawcett e Desanto-Madeya (2013, p. 28) reafirmam: "os conceitos do metaparadigma de Enfermagem, identificadores dos fenômenos de interesse da disciplina de Enfermagem, são o ser humano, o ambiente, saúde e enfermagem".

Por tal influência, Nyatanga (1990, p. 16) chega a decretar: "Cada teoria de enfermagem deve abordar quatro conceitos centrais (outro pesquisador conhece tais conceitos como paradigma) ou seja, a pessoa, o meio ambiente, o grau de saúde / doença, e a própria profissão de enfermagem". Tradução minha.

E o que é metaparadigma? Três definições correntes de metaparadigma de Enfermagem podem ser citadas, desde o final dos anos de 1970: "uma Gestalt [...] dentro da disciplina, [...] um mapa orientando o cientista no vasto e geralmente incompreensível mundo" (Hardy, 1978, p. 38); modo de organização e de estruturação dos fenômenos de uma disciplina (Smith, 1979); "o conceito global que identifica o fenômeno de interesse central para a disciplina, a proposição global que descreve os 
conceitos, e a proposição global que formula as relações entre ou por meio dos conceitos" (Fawcett e Desanto-Madeya, 2005, p. 4-5).

Um complicador adicional às declarações de Smith (1979) e de Fawcett e Desanto-Madeya $(2005 ; 2013)$ é o esclarecimento denotativo e conotativo do que seja fenômeno. Do ponto de vista estritamente helênico, o termo phainómenon (fenômeno) e seu plural phainómena (fenômenos) sempre foi utilizado nas concepções de mundo dos chamados pré-socráticos, na filosofia clássica, por Platão, por Aristóteles, pelos pirrônicos ou céticos, pela filosofia helenística e particularmente pelos epicuristas e estoicos. Essa utilização do termo no vocabulário dos pensadores helênicos e seus leitores cultos tinha duas significações gerais, conforme revê Pereira (2013): os objetos físicos sensíveis (tà aisthetá) ou os objetos exteriores (tà ektòs hypokeímena) e, também, as ideias e pontos de vista das pessoas, nelas incluídas os filósofos.

$\mathrm{Na}$ particularíssima obra de Immanuel Kant, Crítica da Razão Pura, há criteriosa distinção entre Phainómenon, Erscheinung $e$ Schein: Phainómenon ou Phaenomenon (fenômeno) designa as manifestações sensíveis pensadas como objetos e segundo a unidade de suas categorias a priori e, portanto, resultantes do nexo entre intuição empírica (sensações resultantes da afecção do objeto em si sobre os sentidos e sintetizadas na imaginação) e intuição pura (formas puras da sensibilidade); Erscheinung (aparecimento, aparição) e derivado do verbo erscheinen (aparecer) refere-se às manifestações sensíveis reais, ou seja, aparição do objeto indeterminado nas intuições empíricas e, portanto, pertencentes à sensibilidade; Schein (aparência, feição, aspecto, ilusão, enganoso, "disfarce ou simulação", fantasmagórico) e derivado do verbo scheinen, ou seja, pare- cer (Kant, 1919; Loparic, 2002, p. 6; Pimenta, 2006).

Porque não há explicitação consolidada sobre a significação de fenômeno ou fenômenos no âmbito da Enfermagem, a que se referem as expressões "fenômenos de uma disciplina" (Smith, 1979), "fenômeno de interesse central para a disciplina" (Fawcett e Desanto-Madeya, 2005), fenômenos de interesse da disciplina de Enfermagem (Fawcett e Desanto-Madeya, 2013). Pesquisadores de Enfermagem seguem o uso helênico generalizado, seguem algum outro uso específico no campo filosófico, distinguem-se de todos os demais usos por alguma diferenciada significação? Tal questionamento exige uma investigação a parte.

A par da lacuna sobre a significação de fenômeno e fenômenos no âmbito da Enfermagem, para Fawcett e Desanto-Madeya (2013, p. 5) um metaparadigma tem a função de sumarizar a missão social e intelectual da disciplina e delimitar o seu assunto, tendo por requisitos: "identificar um domínio característico dos domínios de outras disciplinas; [...] englobar todos os fenômenos de interesse da disciplina de maneira parcimoniosa; [...] ter uma perspectiva neutra; [...] deve ter substância e extensão global”. A parcimônia refere-se a não redundância de conceitos e de proposições; a neutralidade refere-se a não específicos paradigmas, modelos conceituais, visões de mundo ou combinação de visões de mundo; a globalidade de substância e extensão refere-se a não nacionalidade, culturalidade, crenças étnicas e valores para os conceitos e proposições.

A concepção de Fawcett, publicada originalmente em 1984, influencia várias produções de Enfermagem, inclusive no Brasil onde não se pode afirmar que haja seguimento dos requisitos evocados. No todo ou em partes, a concepção de Fawcett tem sido revista por ou- 
tras pesquisadoras. Por exemplo e desde 1979, Barnum (1994) exclui o conceito de ambiente e defende o conceito de pessoa para abranger o ser humano e o paciente; Schultz (1987, p. 71) adota o conceito de cliente para significar "pluralidades de pessoas e unidades internas, tais como famílias, grupos e comunidades".

Além das investigações de Jacqueline Fawcett, de Bárbara Stevens Barnum e de Phyllis R. Schultz, um quarto exemplo é encontrado em Afaf Ibrahim Meleis num capítulo específico de publicação de 1985, revista, ampliada e reeditada nos anos de 1991, 2005, 2007 e 2012. Neste específico capítulo, a pesquisadora enumera as várias concepções das enfermeiras estadunidenses sobre os conceitos centrais da Enfermagem e explicita o pressuposto perspectivo de que, indissociavelmente, Enfermagem é uma ciência humana, uma disciplina orientada pela tradição prática de cuidado e uma disciplina orientada para a saúde. Nestes termos, a referida pesquisadora distingue e interrelaciona domínio e conceitos centrais, sem utilizar-se dos conceitos de paradigma e metaparadigma.

Domínio é "o cerne de uma disciplina, [...] um território com limites teóricos e práticos”. Do ponto de vista de Meleis, o domínio de uma disciplina científica, incluindo-se a Enfermagem, "é revisado e desenvolvido mediante o saber e a experiência dos membros da disciplina, mediante pesquisa e teoria acumuladas, e mediante o conhecimento desenvolvido em outras disciplinas" (Meleis, 2012, 94-6). Para este ponto de vista, Meleis evoca aspectos das concepções dos pesquisadores estadunidenses Talcott Edgar Frederick Parsons, Thomas Kuhn, Robert King Merton e do britânico Stephen Edelston Toulmin

Para a mesma autora e atentando-se para as influências orientadoras de suas concepções e por ela mesma citadas, os conceitos centrais para todos aqueles domínios são "cliente de Enfermagem, processo de Enfermagem, terapêuticas de Enfermagem, mudanças, ambiente, saúde, interação" (Meleis, 2012, 97).

\section{Procedência das noções de paradigma e me- taparadigma}

No itinerário das pesquisadoras norteamericanas de Enfermagem e sua influência na Enfermagem brasileira, pouco ou nada se refletiu sobre as discussões consequentes de, pelo menos e supostas, vinte e uma significações de paradigma, expostas por Thomas Kuhn, identificadas e comentadas por Margaret Masterman, posteriormente esclarecidas pelo próprio Kuhn. Nesse momento, tornar-se-ia pouco útil repassar as vinte e uma significações, já plenamente conhecidas e discutidas nos meios científicos.

Thomas Kuhn menciona a identificação feita por Margaret Masterman e resume duas significações mais gerais, atribuindo à maioria das outras a diferenças por "inconguências estilísticas”. Primeira significação: "um paradigma é aquilo que os membros de uma comunidade partilham e, inversamente, uma comunidade científica consiste em homens que partilham um paradigma” (Kuhn, 1970 , p. 176).

Parágrafos adiante, Kuhn (1970, p. 182) fala da impropriedade de chamar paradigma o que os membros de comunidade científica partilham. Provisoriamente, designa este o quê se partilha de "matriz disciplinar" e não de teoria ou teorias: "todos ou quase todos os objetos de compromisso grupal que meu texto original designa como paradigmas, partes de paradigma ou paradigmáticos, constituem essa matriz disciplinar e como tais formam um todo, funcionando em conjunto" (Kuhn, 2001, p. 219, 226-7). 
Dentre os componentes de uma matriz disciplinar, Kuhn (2001, p. 227-232) rotula e destaca quatro: as "generalizações simbólicas" ou "componentes formais ou facilmente formalizáveis" em forma de palavras ou de símbolos geralmente matemáticos; os "modelos heurísticos" ou "compromissos coletivos com crenças como: o calor é a energia cinética das partes constituintes dos corpos"; "valores", dentre os quais estão (a) as predições das teorias, (b) valores para julgamento de teorias completas, (c) valores sobre a utilidade social que a ciência deve ou não ter, $(\mathrm{d})$ valores compartilhados por pesquisadores divergentes quanto à aplicação de uma matriz disciplinar; exemplares, ou seja, "as soluções concretas de problemas que os estudantes encontram desde o início de sua educação científica, seja nos laboratórios, exames ou no fim dos capítulos dos manuais científicos, [...] soluções técnicas de problemas encontráveis nas publicações periódicas que os cientistas encontram durante suas carreiras como investigadores".

Segunda significação: paradigmas são "exemplares" tipicamente organizados e compartilhados da denominada "ciência normal" para a solução concreta de quebra-cabeças. Para Kuhn (2001, p. 232-3)

o conhecimento científico está fundado na teoria e nas regras; os problemas são fornecidos para que se alcance destreza daquelas. Todavia, tentei argumentar que esta localização do conteúdo cognitivo da ciência está errada. O estudante que resolveu muitos problemas pode apenas ter ampliado sua facilidade para resolver outros mais. Mas, no início e por algum tempo, resolver problemas é aprender coisas relevantes a respeito da natureza. Na ausência de tais exempla- res, as leis e teorias anteriormente aprendidas teriam pouco conteúdo empírico.

Nesse itinerário da segunda significação, emergem duas consequências. Primeira: o conteúdo cognitivo da atividade científica não se funda em teorias e regras ou métodos pre-estabelecidos ou consolidados. Se assim o fosse, não haveriam novas descobertas, mas reafirmação ou justificação do que anteriormente já está conhecido, afirmado, aceito. Segunda: anteriores a conceitos, a teorias e a leis pre-estabelecidos ou consolidados, os paradigmas são inventados, consolidados, compartilhados e seguidos até certo ponto ou momento em que novos conteúdos empíricos são apresentados, exigindo a constituição de outro "exemplar" para o "quebra-cabeça" dos fatos, diante dos quais e por competição e por persuasão formam novos paradigmas.

O fundamento heurístico do paradigma é a base para a tese de Kuhn de que a ciência ou o conhecimento científico não é produto da "acumulação de descobertas e invenções individuais, [...], dos ditames da observação e do método científico, [mas, da] incomensurabilidade de suas maneiras de ver o mundo e nele praticar a ciência”. E, mais: "revoluções científicas [são] episódios extraordinários nos quais ocorre [...] alteração de compromissos profissionais. As revoluções científicas são os complementos desintegradores da tradição à qual a atividade da ciência normal está ligada" (Kuhn, 2001, p. 21, 23, 25). Se o conhecimento fosse por acumulação de conhecimentos, de invenções e de descobertas, nenhuma revolução científica ter-se-ia dado no campo da história humana.

Muito anteriormente a Thomas Kuhn, o filósofo e historiador alemão Wilhelm Dilthey (1833-1911) criara a teoria das concepções 


\section{Cultura de las Cuidadas}

de mundo (Weltanschauung) e publicada originalmente em 1911, demonstrando a incomensurabilidade aparente de tais concepções e encontrando nexos milenares distintivos entre as mesmas. Por tais nexos, tipifica-as em concepção poética, religiosa e filosófica de mundo, sendo que esta última se diferencia em concepção naturalista da qual o materialismo e o positivismo são derivações, em concepção idealista da liberdade e da personalidade, em concepção idealista objetiva. O nexo (Zusammenhang) entre todas as concepções filosóficas é o fato de serem metafísicas. Metafísica é a reflexão que tem como supostos prévios explicações singulares e deduz as determinações gerais de toda conexão cósmica. [...] A reflexão metafísica analisa no mundo exterior a conexão da realidade. Certamente, esta conexão achava-se fundada, em última instância, na consciência e constituía, com o mundo histórico, o todo da realidade. Sem embargo, o pensamento metafísico dos gregos captou esta conexão no estudo do mundo exterior. Isto teve por consequência o vínculo dos conceitos metafísicos à intuição espacial (Dilthey, 1949, p.148).

Sem negar a função histórica de desenvolvimento da Metafísica até o século XIX no pensamento europeu, constata-se que

historicamente, tem-se desenvolvido um número ilimitado de tais sistemas metafísicos, combatendo-se e excluindo-se reciprocamente em todo tempo. [...] A variedade das formas humanas de existência corresponde à multiplicidade de modos de pensar, de sistemas religiosos, de ideias morais e de sistemas metafísicos. Esta é uma realidade histórica. Os sistemas filosóficos caminham com os

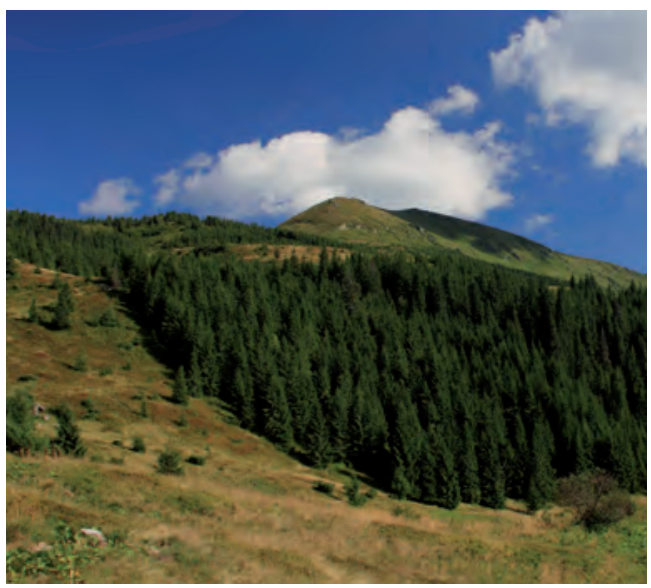

costumes, as religiões, as constituições, manifestando-se, portanto, como produtos condicionados historicamente. [...] As contradições entre os sistemas radicam-se na pluralidade de aspectos da vida, expressos nas formas capitais daqueles. [...]

Os sistemas acham-se atravessados de contradições e de conclusões falsas; selecionam um aspecto das coisas e eliminam os demais; mutilam o vivo em virtude uma vontade poderosa. Apesar de sua fragilidade lógica, vivem graças à energia de um pensamento fundamental e a uma complexidade de ânimo operante nele. Surpreendente é o pouco assombro produzido por tal circunstância. Em lugar de ver as coisas como são, a maioria dos historiadores ocultam por detrás de um mera seriação dos sistemas ou por detrás de algumas uniões lógicas artificiosas e extrinsecas (Dilthey, 1954, p. 3, 5, 6, 8, 31).

Duas explicitações referentes à citação textual de Dilthey. Primeira, deve-se lembrar que sistemas significam conexões de fim ou nexos finais (Zweckzusammenhang) da cultura, conhecidos pelos conceitos gerais de Arte, Ciên- 
cia, Filosofia, Religião; são "uma espécie de seres vivos, em luta recíproca, como ocorre com as criaturas vivas. [...] A exposição de um sistema consistiu até agora nada mais que o intento de encobrir suas lacunas, contradições, etc., mediante um arranjo lógico" (Dilthey, 1954, p. 33, 35). A segunda explicitação é quanto a observação final referente aos historiadores em geral, extensiva aos denominados filósofos e historiadores da história e da ciência: tanto história da religião, da arte, da ciência, "a história da filosofia representa [...] o cenário [...] de teorias excludentes, orientadas para a solução dos problemas" (Dilthey, 1954, p. 79).

Conquanto neste texto o itinerário não é estabelecer comparações entre os dois filósofos, a concepção de paradigma em Thomas Kuhn traz subjacente e em grande medida várias constatações da teoria das concepções de mundo e suas consequências, exaustivamente pesquisadas por Wilhelm Dilthey. O destaque a Wilhelm Dilthey e a Thomas Kuhn quer acentuar a intransponível necessidade de aprofundar-se nas proveniências de concepções de mundo de quantos formulam as suas teorias e modelos teóricos.

$\mathrm{O}$ investimento teórico das pesquisadoras norteamericanas em adotar ou criar metaparadigmas de Enfermagem procede não da própria nominação de Masterman (1979, p. $79,80)$ quando a mesma classifica as supostas várias concepções de Kuhn sobre paradigma em três tipos: "paradigmas metafísicos ou metaparadigmas", "paradigmas sociológicos" e "paradigmas de artefato ou paradigmas de construção".

Na mesma referência já citada e resumidas no quadro 1, Mastermann chama de metaparadigmas o que Thomas Kuhn qualifica de conjunto de crenças, mitos, especulações metafísicas bem sucedidas, modelos, novos modos de ver, princípios organizadores e governantes da percepção, mapas, algo determinante de uma grande área de realidade; paradigmas sociológicos são o que Kuhn qualifica de realização científica universalmente reconhecida, realização científica concreta, conjunto de instituições políticas, decisão judicial aceita; paradigmas de artefato ou de construção são o que Kuhn qualifica de verdadeiro manual ou obra clássica, fornecedor de instrumentos, instrumentação real, paradigma gramatical do ponto de vista linguístico, do ponto de vista ilustrativo como analogia, do ponto de vista psicológico como figura de Gestalt.

Tendo por fio condutor a interpretação, adequada ou não, de Mastermann para metaparadigma, tem-se a introdução deste conceito na Enfermagem pelas pesquisadores anteriormente citadas: "uma Gestalt [...] dentro da disciplina, [...] um mapa orientando o cientista no vasto e geralmente incompreensível mundo" (HARDY, 1978, p. 38); modo de organização e de estruturação dos fenômenos de uma disciplina (Smith, 1979); "conceito global que identifica o fenômeno de interesse central para a disciplina, a proposição global que descreve os conceitos, e a proposição global que formula as relações entre os conceitos ou por meio deles" (Fawcett e Desanto-Madeya, 2005, p. 4).

Pelo exposto, não há similaridade conceitual das significações de metaparadigma em Margaret Mastermann com as conceituações de M. E. Hardy, de Jacqueline Fawcett, de Marilyn M. Rawnsley. Nas características de metaparadigmas consideradas por Fawcett e Desanto-Madeya (2005) há, de modo adequado ou não, fusão entre os três tipos distintos de paradigmas, segundo a interpretação de Mastermann. Deve-se relembrar que, posteriormente, o próprio Kuhn (1970) reviu suas explanações, distinguindo paradigma de matriz 
disciplinar e explicitando alguns componentes dessa matriz.

Não há, portanto, até o momento, generalizações possíveis ou cabíveis nem consensos mundiais sobre metaparadigma de Enfermagem. Nesse itinerário, uma posição e crítica radicais foram feitas no ano de 1998:

Em nossa opinião, os debates sobre metaparadigma tem mais criado divisões teóricas dentro de enfermagem do que definir claramente a nossa missão única e facilitar a comunicação eficaz entre os enfermeiros. Porque nós nos tornamos convencidos de que o efeito mais prejudicial dos debates sobre a pessoa, saúde, meio ambiente e de enfermagem é criar discórdia e falta de comunicação dentro de enfermagem, acreditamos que nossos conceitos centrais deveriam ser caracterizados pela neutralidade paradigmática e uso corrente. Propomos, portanto, definições que reflitam o meio termo e permitam uma gama de posições filosóficas dentro de um núcleo comum de propósito. Em nosso ponto de vista:

Enfermagem é o estudo dos processos de saúde e doença humana. A prática de enfermagem busca facilitar, apoiar e ajudar indivíduos, famílias, comunidades e / ou sociedades para melhorar, manter e recuperar a saúde, e para reduzir e atenuar os efeitos da doença. A prática e a ciência relacional de enfermagem são dirigidas para o resultado explícito de qualidade de vida relacionada à saúde dentro dos contextos ambientais imediatos e maiores (Thorne et al, 1998, p. 1265). Tradução minha

Sem necessariamente adotar a definição de Enfermagem assumida no artigo assinado por
Sally Thorne, Connie Canam, Susan Dahinten, Wendy Hall, Angela Henderson e Sheryl Reimer Kirkham, a posição dessas autoras sobre metaparadigma não interrompe as investigações sobre o tema e pode ser considerada uma evidência da multiplicidade e até incompatibilidade de concepções de mundo e a luta por hegemonia das mesmas, inclusive no âmbito da Enfermagem.

\section{Paradigmas, metaparadigmas, concepções de mundo}

Os denominados paradigmas de Thomas Kuhn e metaparadigmas de Margareth Mastermann são sistematizados anteriormente por Dilthey sob o conceito de concepções de mundo e seus tipos fundamentais: poético, incluindo todas as expressões e gêneros artísticos; religioso; filosófico.

O paradigma filosófico tem dois subtipos: o naturalista e do qual o materialismo e o positivismo são derivações; e o idealista subdimensionado em idealismo da liberdade e da personalidade e idealismo objetivo. Idealismo é todo sistema fundado no conhecimento filosófico da conexão da consciência. Este idealismo é subjetivo quando e na medida em que limita os fatos da consciência ao conhecimento filosófico. [... O] idealismo se torna objetivo quando pretende colocar como base explicativa do universo a conexão do espírito: neste sentido idealismo objetivo é toda filosofia que mostra uma conexão espiritual na realidade exterior e trata de torna-los compreensíveis mediante [aquela conexão espiritual] o sentido desta realidade [exterior] (Dilthey, 1954, p.233).

Todos os paradigmas são históricos porque são criações humanas em diversos momen- 
tos da história e, igualmente, são científicos no sentido e no momento em que se tornam conhecimentos sistematizados: ou seja, não há, em Dilthey, uma concepção metafísica de ciência e muito menos de método. Todos os subtipos do paradigma filosófico são metafísicos. O fundamento metafísico é superado nas Ciências do Espírito (humanas e sociais) pela consciência histórica. Dessa superação emerge o paradigma histórico e com suas várias ramificações derivadas da pluralidade de concepções históricas de mundo.

O quadro 1 resume as características fun- damentais de cada concepção de mundo ou paradigma, características apresentadas e estudadas por Dilthey $(1954 ; 2003)$, excetuando-se a concepção histórica. A importância de tais características é demonstrar o nexo entre a multiplicidade de concepções de mundo, multiplicidade esta geradora de incontáveis concepções de mundo particulares de seus criadores. Por não ser uma mera tipificação, expressa o desenvolvimento histórico do pensamento humano e suas sistematizações doutrinárias sobretudo pelo pensamento ocidental.

Do ponto de vista helênico, o naturalis-

Quadro 1 - Tipos de concepções de mundo

\begin{tabular}{|c|c|}
\hline $\begin{array}{l}\text { Concepções de } \\
\text { mundo }\end{array}$ & Características fundamentais \\
\hline poética & $\begin{array}{l}\text { ponto de partida: a vida; núcleo: referências, conexões vitais com as pessoas, as coisas, a natureza; } \\
\text { instrumento e mediação: a linguagem; material cognitivo: experiência sensível, imaginação, fantasia; } \\
\text { objetivo: conhecer o significado do que acontece, dos homens, dos destinos e das coisas em suas redes vitais; } \\
\text { não objetivo: conhecer a realidade da mesma forma que a ciência }\end{array}$ \\
\hline religiosa & $\begin{array}{l}\text { - origem: experiências cotidianas e recorrentes do nascimento, da morte, da enfermidade, do sonho, da } \\
\text { loucura, das intervenções malignas e saudáveis dos deuses, dos fenômenos da natureza, contemplação do céu, } \\
\text { do sol, dos astros. } \\
\text { - ideia elementar: força atuante do invisível; base cognitiva: pensamento analógico; expressões da vivência } \\
\text { decorrentes da relação religiosa das coisas e das pessoas concretas com o invisível: lugares sagrados, pessoas } \\
\text { santas, imagens de deuses, símbolos, escrituras pictórico-simbólicas, sacramentos ou mistérios, vida } \\
\text { eremítica, profetismo... } \\
\text { - fundamento de coesão e de desenvolvimento: a tradição; características das formações típicas das } \\
\text { concepções religiosas: oposição entre seres benéficos e maléficos, existência sensível e mundo superior; } \\
\text { etapas prévias e pontos de apoio das concepções religiosas para o desenvolvimento posterior da metafísica: } \\
\text { monoteísmo judaico-cristão, panenteísmo chinês e indostânico (região meridional da Ásia). } \\
\text { - evidências da conexão entre concepção religiosa e metafísica: do monoteísmo à teologia escolástica dos } \\
\text { pensadores judeus, árabes e cristãos até Descartes, Wolff, Kant e os filósofos da reação do século XIX; crença } \\
\text { fundamental: nas coisas e nas pessoas existe a presença de uma energia suprassensível. }\end{array}$ \\
\hline $\begin{array}{l}\text { filosófica } \\
\text { naturalista }\end{array}$ & $\begin{array}{l}\text { - conhecimento causalista; Gnoseologia: fato dominante = sensualismo, ou seja,_ "redução do processo de } \\
\text { conhecimento ou de suas operações à experiência sensível exterior e das determinações de valor e fins ao } \\
\text { critério de valor contido no prazer e dor sensíveis. [...] A primeira teoria do Sensualismo foi criada por } \\
\text { Protágoras" (DILTHEY, 1954, p. 132-3). } \\
\text { - Metafísica: dirigida pelo materialismo; ao permanecer nos limites da experiência refutando a metafísica, } \\
\text { adotará no século XIX a forma de Positivismo. } \\
\text { - Conhecimento da natureza precede o estudo do Homem; auxiliado pela matemática e pelo experimento, } \\
\text { investiga o mundo físico e descobre leis regedoras do cosmos; a matéria é realidade absoluta. Se a matéria é } \\
\text { substância última do real torna-se materialismo; se a matéria possui apenas caráter fenomenal é positivismo. } \\
\text { - Mundo: é totalidade causalmente determinada na qual descartam-se conceitos de liberdade, de valor, de fim; } \\
\text { O espiritual é explicado pelo físico e a ele se subordina; o Homem por suas paixões é escravo da natureza e } \\
\text { adquire consciência de sua situação pela força do pensamento. }\end{array}$ \\
\hline $\begin{array}{l}\text { filosófica } \\
\text { idealista objetiva }\end{array}$ & $\begin{array}{l}\text { - Experiência íntima e valor; Mundo concebido como espírito, Deus, valor; Realidade: expressão de algo } \\
\text { intimo; constitui o desprendimento espontâneo de uma força espiritual atuante (consciente ou } \\
\text { inconscientemente); Nalguns subsistemas, o motivo religioso domina (universo é explicatio Dei): Panteísmo e } \\
\text { Panenteísmo são formas desses subsistemas. } \\
\text { - Homem: está em estreita afinidade com a natureza mediante atitude contemplativa, estética ou mística; } \\
\text { Plenitude da vida afetiva e realização da felicidade da existência humana: nasce dos valores do belo, do } \\
\text { verdadeiro e do bem }\end{array}$ \\
\hline
\end{tabular}

Fonte: o autor 
mo se representa por Demócrito de Abdera, incluindo posteriormente os Enciclopedistas, os materialistas modernos, os positivistas e os neopositivistas; o idealismo de liberdade se representa por Anaxágoras de Clazómenas, os Apologistas, os padres cristãos, Immanuel Kant, Henri Bergson e o Personalismo; o idealismo objetivo se representa por Parmênides de Eléia e Heráclito de Éfeso, Georg Wilhelm Friedrich Hegel, os fenomenologistas e os existencialistas.

Pela tipificação de Dilthey das concepções de mundo e suas características fundamentais tornar-se-á mais facilitada uma possível e talvez necessária tarefa de identificar o paradigma subjacente à multiplicidade de conceitos e de propostas teóricas presentes e defendidas na pluralidade dos escritos de Enfermagem. Fora dessa tipificação o que se encontra é uma pluralidade de escritos, cada qual com sua concepção de mundo e buscando generalizações inadequadas para hegemonização dessa ou daquela concepção.

\section{Conclusão propositiva}

Independente de qual seja a concepção de mundo ou o paradigma e sem entrar na disputa conceitual sobre os metaparadigmas de Enfermagem, dois conceitos substantivos persistem nos 120 escritos nacionais de Enfermagem, analisados entre 1985 e 2014 para o processo de doutoramento em curso: corpo e cuidado, interligados pelo conceito conjuntivo de relacionamento terapêutico. Por esse conceito conjuntivo ou correlatos, forma-se estrita e caracteristicamente um conceito adjetivo: cuidado de Enfermagem - um conceito sinonímio à art of nursing, segundo Nightingale (1860), arte de enfermeira ou arte de Enfermagem.

Uma observação evidenciável em todos os livros e artigos estadunidenses de Enferma-

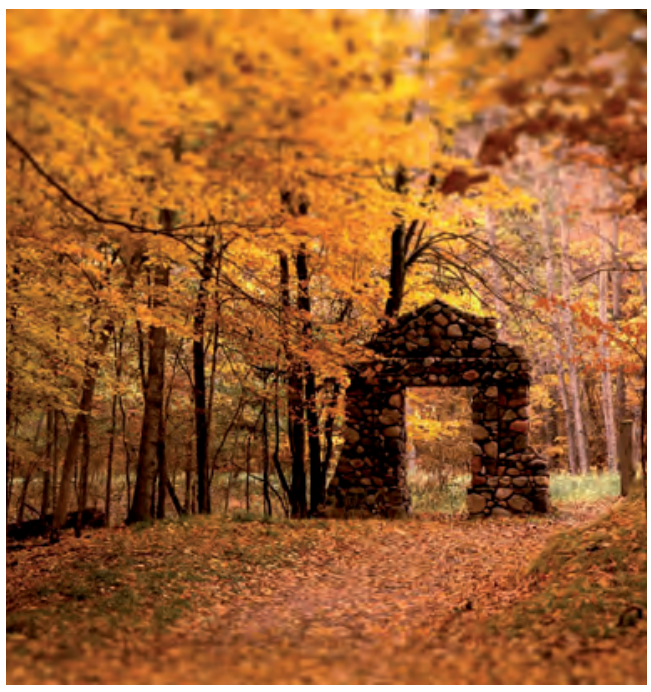

gem é a não focalização do corpo como conceito substantivo e do qual procedem todos os demais e isto apesar do fato de que o eixo 4 , localização, da classificação dos diagnósticos de Enfermagem (NANDA, 2015, p. 90) referir-se ao corpo, descrevendo "as partes/regiões do corpo e/ou funções relacionadas - todos os tecidos, órgãos, locais ou estruturas anatômicas".

No âmbito estrito da Enfermagem e no relacionamento terapêutico, iniciado em situações específicas e profissionais, corpo e cuidado criam cuidado de Enfermagem. Ou seja, o conceito cuidado de Enfermagem não é uma abstração nem resulta de uma produção teórica: dito de outro modo, cuidado de Enfermagem é um conceito aDStraído e não aBStraído da vivência (Erlebnis). Independente de quaisquer cenários, aquele relacionamento terapêutico e consequentemente o cuidado de Enfermagem expressam-se em dimensões gerenciais, educacionais, assistenciais, de pesquisa.

Num parêntese explicativo, AB (A, ABS) é prefixo latino com a significação de distanciamento, separação, a partir de, depois de e AD (ADS) é prefixo latino com a significação de movimento para; em direção a; aproximação. 
A tríade corpo - relacionamento terapêutico - cuidado, criando cuidado de Enfermagem, traz em si uma conexão ainda mais originária, substantiva e histórica: a vivência (Erlebnis). Nesse itinerário, são sinonímios vivência, vida (Leben) constitutivamente histórico-humana, viver (Erleben), vivenciar ou experiência vivida. A vida histórica e humana se dá temporalmente no processo vida-morte e é dentro desse processo que se vivenciam experiência de saúde e de doença; ou seja e do ponto de vista da Enfermagem, processo vida-morte é mais fundamental que o preconizado processo saúde-doença.

Com outras palavras ou expressões, a fundamentalidade da vivência para a constituição, consolidação e desenvolvimento da ciência da Enfermagem foi inicial e formalmente defendida pelas pesquisadoras Bárbara Carper e Patrícia Benner, em publicações de 1978 e 1984 respectivamente: o desenvolvimento da disciplina científica de Enfermagem procede das experiências profissionais da área, ou seja, do exercício profissional no trabalho de Enfermagem (Carper, 1978; Benner, 1984). Muitos confundem a fundamentalidade da vivência com um fazer-por-fazer ou numa concepção teoria versus prática, o que deu margem à concepção de Enfermagem como uma disciplina centrada em técnicas e procedimentos, cujas explicitações e críticas foram realizadas por Almeida e Rocha (1986), ou de uma disciplina aplicada, não teórica.

Pelo exercício profissional no trabalho de Enfermagem, a historicidade (em alemão, historizität) do corpo - relacionamento terapêutico - cuidado de Enfermagem não é deduzida nem inferida porque tanto não existe realidade humana-histórica-social sem corpo quanto não existe cuidado de Enfermagem sem corpos humanos que o criem fora daquele rela- cionamento terapêutico: esses corpos são vida e história, não são discursos ou abstrações de um pensamento desencarnado e a-histórico. Por isso a sinonimização vivência (Erlebnis), vida (Leben), viver (Erleben), vivenciar ou experiência vivida.

Esta vivência, expressa em cuidado de Enfermagem, é vivência de corpo. Porque tais expressões são realizadas no corpo, pelo corpo e para o corpo, o corpo é um conceito substantivo, sobretudo porque não existe, da concepção à morte, vida histórica e humana aquém ou além do corpo.

$\mathrm{Na}$ vida histórica, humana e necessariamente corpórea, o que se denomina prática ou trabalho de Enfermagem é cuidado de Enfermagem, em quaisquer dimensões: gerenciais, educacionais, assistenciais, de pesquisa. Eis o porquê de se propor igualmente o cuidado como conceito substantivo, sendo que no campo disciplinar específico o conceito adjetivo é cuidado de Enfermagem.

De inúmeras outras formas, com outros termos ou expressões e traduzindo concepções variáveis, os conceitos de corpo e de cuidado são destacados na Enfermagem; no entanto, é incomum e possivelmente inédita a radicalidade histórica se enunciar que não existe vida histórica e humana sem corpo tanto quanto não existe aquela mesma vida histórica e humana sem cuidado. Ou seja, corpo e cuidado não são fenômenos, epifenômenos, alteregos, simbologias, representações, construções sociais. Isto tudo o que corpo e cuidado não são expressam concepções de não corpo e concepções de não cuidado. Tal realidade e radicalidade histórica não é questão de teorias nem de métodos porque a vida histórica e humana não é um processo teórico, ainda que teorizável.

Tais conclusões são consequentes à pesquisa de doutoramento em curso e na qual o ob- 


\section{ᄃultura de las ᄃuidados}

jeto de estudo é o corpo mediador do cuidado de Enfermagem. Nesse itinerário conclusivo e em termos aristotélicos, para a Enfermagem o corpo é causa material, o corpo mediador é causa formal, o relacionamento terapêutico no processo de cuidado é a causa eficiente e o cuidado de Enfermagem é a causa final.

\section{REFERÊNCIAS}

- ANA (1980). Nursing: A social policy statement. Kansas City M.O: American Nurses Association.

- Almeida, M.C.P., Rocha, J.S.Y. (1986). O Saber de Enfermagem e sua dimensão prática. São Paulo: Cortez,

- Barnard, K.E. (1980). Knowledge for practice: directions for the future. Nursing Research, 29(4), 208-212.

- Barnum, B.S. (1994). Nursing theory: Analysis, application, and evaluation ( $\left.4^{\mathrm{a}} \mathrm{ed}\right)$. Philadelphia:Lippincott,

- Benner, P. (1984). From novice to expert: power and excellence in nursing practice. Menlo Park, CA: AddisonWesley.

- Bush, H.A. (1979). Models for nursing. Advances in Nursing Science, 1(2), 13-21.

- Carper, B. (1978). Fundamental patterns of knowing in nursing. In Nicoll, L.H. Perspetives on nursing theory. Philadelphia: Lippincot.

- Chinn, P.L. (1983). Advances in nursing theory development. Rockville, Maryland: Aspen Systems Corporation.

- Dilthey, W. (1914). Der Aufbau der geschichtlichen Welt in den Geisteswissenschaften. GS VII. Göttingen: Vandenhoeck \& Rupecht.

- Dilthey, W. (1944). El Mundo historico. (1 ${ }^{a}$ ed. en espanhol). México: Fondo de Cultura Economica.

- Dilthey, W. (1949). Intoduccion a las ciencias del espíritu: en la que se trata de fundamentar el estudio de la sociedad y de la historia. ( $2^{\text {a }}$ ed. en espanhol. Trad. Eugenio Ímaz. México: Fondo de Cultura Económica.

- Dilthey, W. (1951). Psicologia y teória del conocimiento. México D.F; Fondo de Cultura Económica.

- Dilthey, W. (1954).Teoria de la concepcion del mundo. Trad. Eugenio Ímaz. México D.F.: Fondo de Cultura
Económica.

- Dilthey, W. (2003). La Esencia de la Filosofia. Trad. Elsa Tabernig. Buenos Aires: Losada.

- Dilthey, W. (2010). A construção do mundo histórico nas ciências humanas. Trad. Marco Antônio Casanova. São Paulo: Unesp.

- Dilthey, W. (2012). Lédification du monde historique dans les sciences de l'esprit. Trad. Sylvie Mesure. Paris: Cerf/ Centre National des Lettres.

- Flaskerud, J.H., Halloran, E.J. (1980). Areas of agreement in Nursing theory development. Advances in Nursing Science, 3(1), 1-7.

- Fawcett, J. (1984). The metaparadigm of nursing: present status and future refinements. Journal of Nursing Scholarship, 16(3), 84-7.

- Fawcett, J., Desanto-Madeya, S. (2005). Contemporary nursing knowledge: Analysis and evaluation of nursing models and theories. ( $2^{\mathrm{a}}$ ed). Philadelphia (PA): F.A. Davis Co.

- Fawcett, J., Desanto-Madeya, S. (2013). Contemporary nursing knowledge: Analysis and evaluation of nursing models and theories. ( $3^{\mathrm{a}}$ ed). Philadelphia (PA): F.A. Davis Co.

- Hardy, M.E. (1978). Perspectives on nursing theory’. Advances in Nursing Science, 1(1), 37-48.

- Kant, I. (1997). Crítica da razão pura. Trad. Manuela P. dos Santos y Alexandre F. Morujão. Lisboa: Calouste Gulbenkian.

- Kuhn, T.S. (1970). The Structure of Scientific Revolutions. $\left(2^{\mathrm{a}}\right.$ ed). Londres: Universidade de Chicago.

- Kuhn, T.S. (2001). A estrutura das revoluções científicas. (6 ${ }^{\mathrm{a}}$ ed). Trad. Beatriz Vianna Boeira y Nelson Boeira. São Paulo: Perspectiva.

- Loparic, Z. (2002). A semântica transcendental de Kant. ( $2^{\text {a }}$ ed). Campinas: UNICAMP/Centro de Lógica, Epistemologia e História da Ciência..

- Meleis, A.I. (2012). Theoretical nursing: development and progress. ( $5^{\mathrm{a}}$ ed). Filadélfia, Pensilvânia: Wolters Kluwer/ Lippincott Williams \& Wilkins.

- NANDA. (2015). Diagnósticos de Enfermagem da NANDA International: definições e classificação 2012-2014. (10 . ed). Trad. Regina Machado Garcez. Porto Alegre: 


\section{Cultura de las Cuidados}

Artmed.

- Newman, M.A. (1983). The continuing revolution: a history of nursing science. In: Chaska, N.L. (editor). The nursing profession: a time to speak. Nova Iorque: McGraw-Hill.

- Nightingale, F. (1860). Notes on Nursing: what it is and what it is not. Londres: Harrison, 59, Pall Mall.

- Nyatanga, L. (1990). Nursing paradigm: the state of art. Senior Nurse, 10, 18-19.

- Pereira, O.P. (2013). A noção de phainómenon em Sexto Empírico. Analytica, 17(2), 291-323.

- Pimenta, O.C. (2006). A distinção kantiana entre aparecimento e fenômeno. In Kant e-prints. Campinas, Série 2, 1(1), 119-126.

- Rawnsley, M.M. (1996). Response to: "On the requirements for a metaparadigm: an initation to dialogue". Nursing Science Quarterly, 9(3), 102-106.
- Schultz, P.R. (1987). When client means more than one: Extending the foundational concept of person. Advances in Nursing Science, 10(1), p. 71-86.

- Smith, M.C. (1979). Proposed metaparadigm for nursing research and theory development: An Analysis of Orem's Self Care Theory. Image, 11(3), 75-79.

- Stevens, B.J. (1979). Nursing Theory: Analysis, Application, Evaluation. Boston: Little Brown.

- Thorne, S. et al. (1998). Nursing's metaparadigm concepts: disimpacting the debates. Journal of Advanced Nursing, 27(6), 1257-1268.

- Walker, L.O. (1971). Toward a clearer understanding of the concept of nursing theory. Nursing Research. 20(5), 428-35.

- Yura, H.; Torres, C. (1975). Today's conceptual frameworks within the baccalaureate nursing programs. N.L.N. Publication, (15-1558), 17-75.

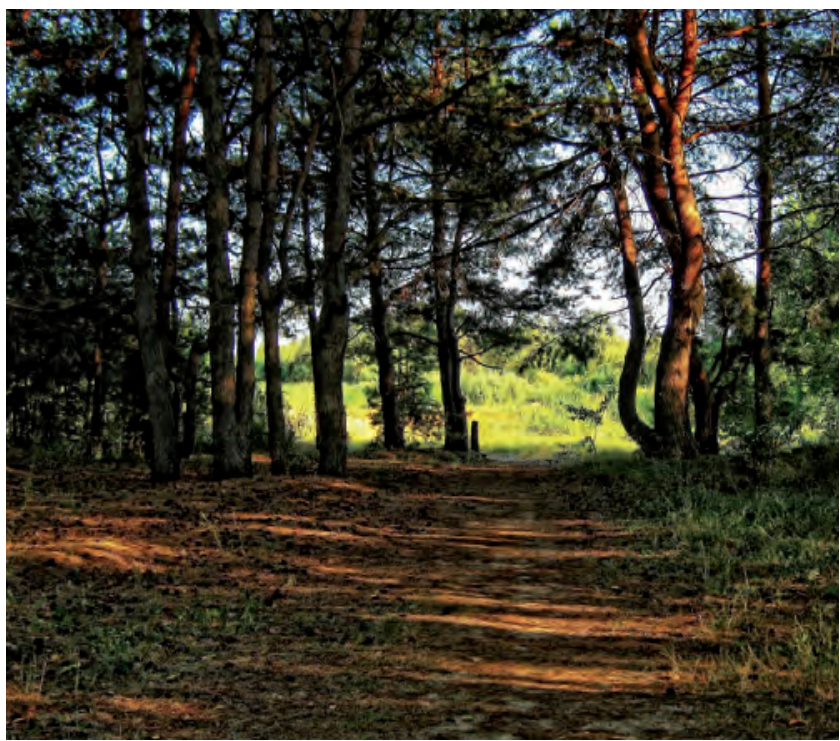

